\title{
Low density of sympathetic nerve fibres and increased density of brain derived neurotrophic factor positive cells in RA synovium
}

\author{
C Weidler*, C Holzer*, M Harbuz, R Hofbauer, P Angele, J Schölmerich, R H Straub
}

Ann Rheum Dis 2005;64:13-20. doi: 10.1136/ard.2003.016154

See end of article for authors' affiliations

.....................

Correspondence to: Professor R H Straub, Department of Internal Medicine I, University Hospital, 93042

Regensburg, Germany; rainer.straub@ klinik.uni-regensburg.de

Accepted

22 February 2004

\begin{abstract}
Objective: To investigate the correlation between density of nerve fibres and the presence of $\mathrm{BDNF}^{+}$cells. Methods: Densities of nerve fibres and $\mathrm{BDNF}^{+}$cells were detected by quantitative immunohistochemistry in fresh synovial tissue from 52 patients with RA, 59 with OA, and 26 controls (Co). BDNF was also detected by in situ hybridisation.

Results: Sympathetic nerve fibre density was similar in Co and OA but markedly reduced in RA $(p=0.002)$, whereas density of substance $\mathrm{P}$ positive $\left(\mathrm{SP}^{+}\right)$sensory nerve fibres was lower in $\mathrm{OA}$ than in $\mathrm{Co}$ and RA $(p=0.002)$. The ratio of sympathetic $/ \mathrm{SP}^{+}$sensory nerve fibre density was highest in $\mathrm{OA}$ and $\mathrm{Co}_{0}$, followed by RA. The correlation between density of sympathetic nerve fibres and $\mathrm{SP}^{+}$sensory nerve fibres in OA $(R=0.425, \mathrm{p}=0.001)$ was strongly positive, had a positive trend in Co $(R=0.243, \mathrm{NS})$, but was negative in RA $(R=-0.292, p=0.040)$. In RA and OA tissue the density of $\mathrm{BDNF}^{+}$cells was high in sublining areas but markedly lower in $\mathrm{Co}(p=0.001)$. $\mathrm{BDNF}^{+}$cell density correlated positively with the ratio of sympathetic/SP+ sensory nerve fibre density in $\mathrm{Co}^{+}(R=0.433, \mathrm{p}=0.045)$ and in $\mathrm{OA}(R=0.613$, $\mathrm{p}=0.015)$, but not in RA $(R=0.101$, NS). Immunohistochemical double staining demonstrated that some macrophages and fibroblasts were positive for BDNF.

Conclusions: The correlation of density of $\mathrm{SP}^{+}$sensory with sympathetic nerve fibres was positive in Co and $\mathrm{OA}$ but negative in RA. BDNF may have a stimulatory role on growth of sympathetic in relation to $\mathrm{SP}^{+}$ sensory nerve fibres in Co and OA, but not in RA.
\end{abstract}

$\mathrm{P}$ eripheral sympathetic neurotransmitters and their cofactors such as norepinephrine, neuropeptide Y (NPY), and adenosine inhibit important inflammatory functions such as, for example, production of tumour necrosis factor by monocytes/macrophages, ${ }^{1-4}$ production of oxygen radicals by neutrophils, ${ }^{5-7}$ and activity of natural killer cells. ${ }^{8-11}$ High concentrations of these neurotransmitters $\left(10^{-7}\right.$ to $10^{-5} \mathrm{~mol} / \mathrm{l}$ via $\beta$-adrenoceptors, Y1 NPY receptors, or A2 adenosine receptors) down regulate many aspects of the innate immune system and, thus the presence of sympathetic nerve fibres should be favourable in the inflamed synovium of patients with rheumatoid arthritis (RA) (reviewed by Straub and Cutolo $\left.^{12}\right)$. However, the density of sympathetic nerve fibres is dramatically reduced in inflamed RA synovium, ${ }^{13}{ }^{14}$ whereas the density of proinflammatory substance $\mathrm{P}$ positive $\left(\mathrm{SP}^{+}\right)$ sensory nerve fibres is increased in the synovium of patients with RA as compared with osteoarthritis $(\mathrm{OA}) .^{15}$

The reasons for the imbalance of the density of sympathetic in relation to $\mathrm{SP}^{+}$sensory nerve fibres is not yet known, but the ratio of neurotrophic factors to nerve repellent factors may have an important role. ${ }^{16}{ }^{17}$ We have recently shown that the sympathetic nerve repellent factor semaphorin $3 \mathrm{C}$ is markedly up regulated in RA synovium as compared with OA or control tissue; this was not observed for nerve repellent factors of sensory nerve fibres. ${ }^{18}$ This might lead to a decrease of sympathetic nerve fibres in RA as compared with OA and controls. However, there is no good explanation why the density of sympathetic nerve fibres is higher in OA than in RA or controls. It is unlikely that the repellent factors of the semaphorin group play a part because repellent factors of sensory neurons were not detected in the tissue of all subgroups. On the other hand, changes of expression of

${ }^{*} \mathrm{C}$ Weidler and C Holzer contributed equally to this study. neurotrophic factors may be responsible for the observed imbalance of sympathetic and $\mathrm{SP}^{+}$sensory nerve fibres.

Since the discovery of the original nerve growth factor (NGF) in the 1960s by Levi-Montalcini, other peripherally acting neurotrophins, such as brain derived neurotrophic factor (BDNF), neurotrophin-3, neurotrophin-4, neurotrophin-5, and ciliary neurotrophic factor, have been described. In addition to their canonical role in promoting neuronal survival and growth, these molecules appear to regulate multiple aspects of the development of the nervous system in vertebrates, including neuronal differentiation, axon elongation, and target innervation. ${ }^{19}$ The growth promoting effects of the above mentioned neurotrophins on sensory or sympathetic neurons are unspecific because their receptors appear on both types of nerve fibres (see for example, Barbacid ${ }^{20}$ and Chalazonitis $^{21}$ ). Interestingly, NGF supports the inflammatory process and it is up regulated during inflammatory episodes in the skin, ${ }^{22}$ in rheumatoid synovium, ${ }^{23}$ and in the bronchial system. ${ }^{24}$ On the basis of its unspecific effects on both types of peripheral nerve fibres, NGF should induce nerve fibre sprouting of sympathetic and sensory nerve fibres. Because only $\mathrm{SP}^{+}$sensory nerve fibres are increased in the inflamed synovium of patients with RA other mechanisms must be responsible for the observed imbalance.

In contrast with NGF, the role of BDNF in inflammation is not precisely known. BDNF is up regulated in rat dorsal root ganglia after acute peripheral inflammation. ${ }^{25}$ Activated cells of the immune system express BDNF upon stimulation, ${ }^{26}{ }^{27}$

Abbreviations: APAAP, alkaline phosphatase-anti-alkaline phosphatase; BDNF, brain derived neurotrophic factor; NGF, nerve growth factor; NPY, neuropeptide Y; OA, osteoarthritis; RA, rheumatoid arthritis; SP, substance $\mathrm{P} ; \mathrm{TH}$, tyrosine hydroxylase 
Table 1 Basic characteristics of all patients with RA and OA

\begin{tabular}{|c|c|c|c|c|}
\hline \multirow[b]{2}{*}{ Characteristic } & \multicolumn{2}{|l|}{ RA } & \multicolumn{2}{|l|}{ OA } \\
\hline & Entire group & Subgroup $\ddagger$ & Entire group & Subgroup $\ddagger$ \\
\hline $\begin{array}{l}\text { Number } \\
\text { Age (years), mean (SEM) [range] } \\
\text { Sex (F/M) } \\
\text { ESR (mm/l st h), mean (SEM) } \\
\text { CRP (mg/l), mean (SEM) }\end{array}$ & $\begin{array}{l}52 \\
65.2(1.3)[39-84] \\
41 / 11 \\
32.0(3.7)^{\star *} \\
27.6(4.4)^{\star *}\end{array}$ & $\begin{array}{l}\{15\} \\
\{66.2(3.4)[39-84]\} \\
\{14 / 1\} \\
\{35.6(8.0) \dagger\} \\
\left\{27.3(8.9)^{*}\right\}\end{array}$ & $\begin{array}{l}59 \\
68.9(1.2)[41-88] \\
43 / 16 \\
15.2(1.4) \\
5.8(0.6)\end{array}$ & $\begin{array}{l}\{17\} \\
\{67.9(3.1)[49-88]\} \\
\{15 / 2\} \\
\{17.3(3.2)\} \\
\{5.1(0.8)\}\end{array}$ \\
\hline $\begin{array}{l}\text { Drugs (No (\%) of patients) } \\
\text { Prednisolone } \\
\text { NSAID } \\
\text { Methotrexate } \\
\text { Leflunomide } \\
\text { Ciclosporin A } \\
\text { Azathioprine } \\
\text { Sulfasalazine } \\
\text { Hydroxychloroquine }\end{array}$ & $\begin{array}{l}43(83) \\
41(79) \\
11(21) \\
4(8) \\
1(2) \\
3(6) \\
5(10) \\
4(8)\end{array}$ & $\begin{array}{l}\{12(80)\} \\
\{13(87)\} \\
\{3(20)\} \\
\{4(27)\} \\
\{1(7)\} \\
\{1(7)\} \\
\{3(20)\} \\
\{3(20)\}\end{array}$ & $\begin{array}{c}1(2) \\
28(47) \\
0(0) \\
0(0) \\
0(0) \\
0(0) \\
1(2) \\
0(0)\end{array}$ & $\begin{array}{l}\{0(0)\} \\
\{8(53)\} \\
\{0(0)\} \\
\{0(0)\} \\
\{0(0)\} \\
\{0(0)\} \\
\{0(0)\} \\
\{0(0)\}\end{array}$ \\
\hline
\end{tabular}

${ }^{*} p<0.05,{ }^{* *} p<0.01,+p=0.07$ for comparison of the two disease groups.

fData in braces are the subgroup characteristics for the immunohistochemistry study on BDNF.

and BDNF has been found in inflammatory lesions in the brain and in the pancreas during pancreatitis. ${ }^{26}{ }^{28}$ However, its expression has never been investigated in arthritic animals or in patients with RA or OA.

This study aimed at investigating the presence of $\mathrm{BDNF}^{+}$ cells in synovial tissue of patients with RA, OA, and traumatic controls. Furthermore, we wanted to investigate a possible relationship between the density of $\mathrm{BDNF}^{+}$cells and the density of sympathetic/SP${ }^{+}$sensory nerve fibres.

\section{PATIENTS AND METHODS}

\section{Patients and controls}

Fifty two patients with RA and 59 patients with OA who underwent knee joint replacement surgery and 26 control subjects with acute trauma who underwent arthroscopic knee surgery were included without further selection. In the original pool of 30 control subjects, four patients had chronic traumatic joint affections. These latter control subjects had clear signs of inflammation so that they were removed from the analysis. The 26 remaining control subjects had acute disease and no visible signs of inflammation. Diagnosis of RA was based on the established American College of Rheumatology criteria. ${ }^{29}$ All patients were informed about the purpose of the study and gave written consent. The study was approved by the ethical committee of the University of Regensburg.
Table 1 shows details of the clinical and laboratory data for the entire group and for the subgroup included in the BDNF immunohistochemical study. Respective control subjects (11 women, 15 men) had a mean (SEM) age of 32.2 (2.4) (range 16-60) years. Patients for the subgroup analysis included in the BDNF immunohistochemistry study are shown in braces in table l. Respective control subjects ( 2 women, 5 men) had a mean (SEM) age of 41.1 (4.9) (16-60) years. Variables such as erythrocyte sedimentation rate, $\mathrm{C}$ reactive protein, and blood leucocyte count were measured by standard techniques. Although our control subjects were markedly younger, we decided to include them in order to present a completely different group without any longstanding inflammation. Furthermore, preliminary correlation analyses indicated that nerve fibre density was not related to age (see also "Results"). This group comprised patients with acute knee joint problems such as tibial plateau fracture, anterior cruciate ligament rupture, and loose bodies in the knee joint.

\section{Synovial tissue preparation and immunohistochemistry}

Synovial tissue samples were obtained immediately after opening the knee joint capsule or during arthroscopic surgery (in controls). The tissue for histology was prepared as described previously. ${ }^{14}$ Synovial tissue pieces of at least $3 \times 3 \mathrm{~mm}^{2}$ were used for histology. Samples intended for
SP

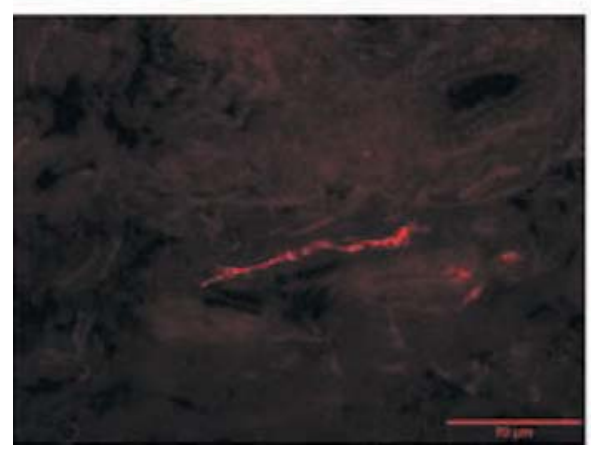

TH

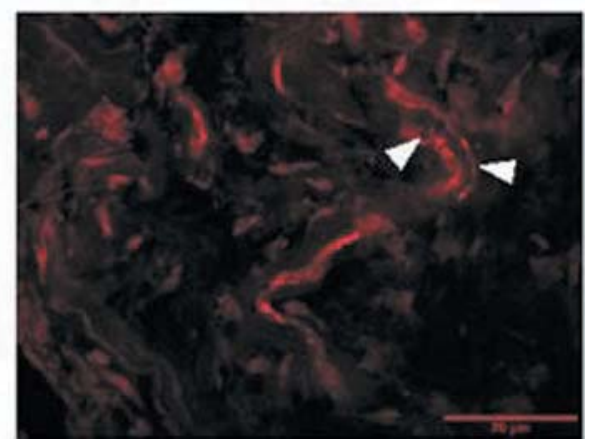

Figure 1 Representative immunohistochemistry of substance $\mathrm{P}$ (SP) positive sensory nerve fibres and sympathetic tyrosine hydroxylase (TH) positive nerve fibres. Note the typical juxtaposition of $\mathrm{TH}$ positive fibres and the structure of an artery (arrow heads). Micrographs were taken at $\times 400$ magnification. 
alkaline phosphatase-anti-alkaline phosphatase (APAAP) staining were immediately placed in protective freezing medium (Tissue Tek, Sakura Finetek, Zoeterwoude, The Netherlands) and then quick frozen by floating on liquid nitrogen. Tissue samples for the detection of nerve fibres were fixed for 12-24 hours in phosphate buffered saline containing $3.7 \%$ formaldehyde, and then incubated in phosphate buffered saline with $20 \%$ sucrose for $12-24$ hours. Thereafter, tissue was embedded in Tissue Tek and quick frozen. All tissue samples were stored at $-80^{\circ} \mathrm{C}$.

Histological evaluation was carried out as described previously. ${ }^{14}$ Briefly, the frozen tissue samples were cut into 5-8 $\mu \mathrm{m}$ thick sections. To determine the number of $\mathrm{BDNF}^{+}$ cells (catalogue No MAB248; R\&D Systems, Wiesbaden, Germany) in the synovial tissue of each patient, eight cryosections were investigated using APAAP staining and the number of identified structures was averaged from 17 randomly selected high power fields of view $(\times 400)$ and expressed per square millimetre. Because we did not have authentic BDNF, we controlled the positive BDNF staining by incubating the tissue with mouse isotype $\operatorname{IgG}$ control antibodies which always yielded a negative result. The determination of synovial innervation has been described previously..$^{14}$ Briefly, six to eight cryosections (5-9 $\mu \mathrm{m}$ thick) of the formaldehyde/sucrose fixed tissue samples were used for immunohistochemistry with a primary antibody against tyrosine hydroxylase $\left(\mathrm{TH}^{+}\right.$, the key enzyme for norepinephrine production in sympathetic nerve endings, catalogue No MAB318; Chemicon, Temecula, CA, USA) and against $\mathrm{SP}^{+}$ (the key neurotransmitter of $\mathrm{SP}^{+}$sensory nerve fibres, catalogue No AB1566; Chemicon). An Alexa 546 conjugated secondary antibody (catalogue No A-11030 against mouse
IgG, catalogue No A-121010 against rabbit IgG; Molecular Probes, Leiden, The Netherlands) was used to achieve immunofluorescent staining of sympathetic and $\mathrm{SP}^{+}$sensory nerve fibres (fig 1). The numbers of $\mathrm{TH}^{+}$sympathetic and $\mathrm{SP}^{+}$ sensory nerve fibres per square millimetre were determined by averaging the number of stained nerve fibres (minimum length $50 \mu \mathrm{m}$, determined through a micrometre eyepiece) in 17 randomly selected high power fields of view $(\times 400)$. We controlled the positive nerve fibre staining by incubating the tissue with polyclonal control antibodies which always yielded a negative result.

\section{Immunofluorescence double staining of $\mathrm{BDNF}^{+}$cells and macrophages/fibroblasts}

Double staining of $\mathrm{BDNF}^{+}$cells and macrophages/fibroblasts was carried out as follows: acetone fixed cryosections were incubated overnight with a polyclonal rabbit antihuman BDNF antibody (catalogue No AB6201-500; Abcam Ltd, Cambridge, UK). Thereafter, fibroblasts and macrophages were stained by mouse monoclonal antibodies against prolyl4-hydroxylase or CDl63 (catalogue No M0877 or M0794; Dako, Glostrup, Denmark). Immunofluorescence staining was achieved with $\mathrm{F}(\mathrm{ab})_{2}$ fragments of goat antirabbit or antimouse IgG (Alexa Fluor 555 or 488, catalogue No. A21430 or A-11017; Molecular Probes, Leiden, The Netherlands). Nuclei were stained with DAPI (Vectashield mounting medium, catalogue No H-1200; Vector Laboratories, Burlingame, USA).

\section{BDNF in situ hybridisation of synovial tissue}

Synovial tissue was stored at $-80^{\circ} \mathrm{C}$ before sectioning $(20 \mu \mathrm{m})$ on a cryostat. Sections (4-6 per tissue) were
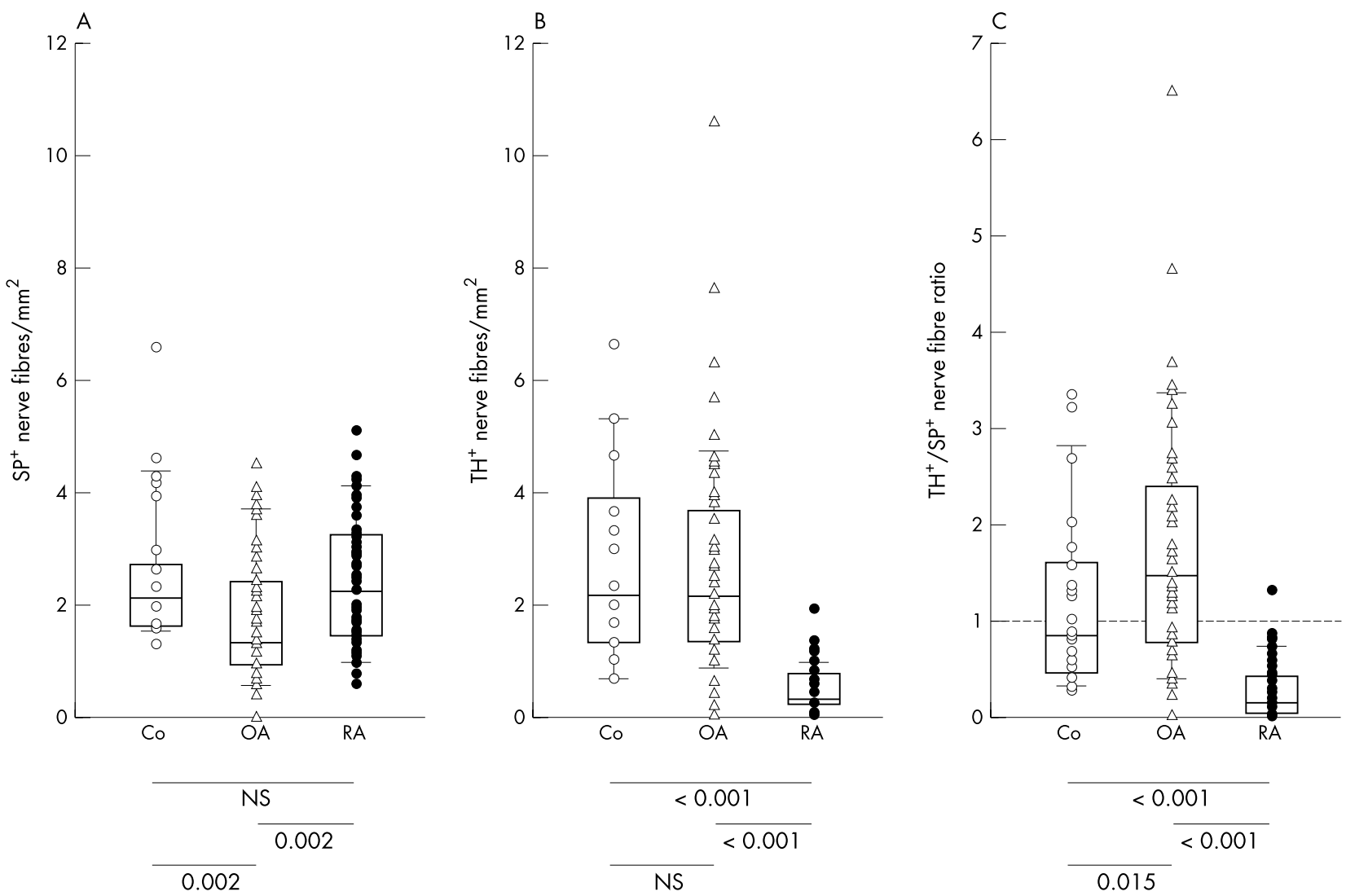

Figure 2 Density of sympathetic and $\mathrm{SP}^{+}$sensory nerve fibres in control subjects $(\mathrm{Co})$, patients with $\mathrm{OA}$, and RA. (A) Density of $\mathrm{SP}^{+}$sensory nerve fibres; (B) density of sympathetic $\mathrm{TH}^{+}$nerve fibres; and (C) ratio of density of sympathetic/SP+ sensory nerve fibres. Values of $\mathrm{p}$ for comparison of group medians are given below the panels. The box plots demonstrate the 10th and 90th centile, the 25th and 75th centile, and the median. 

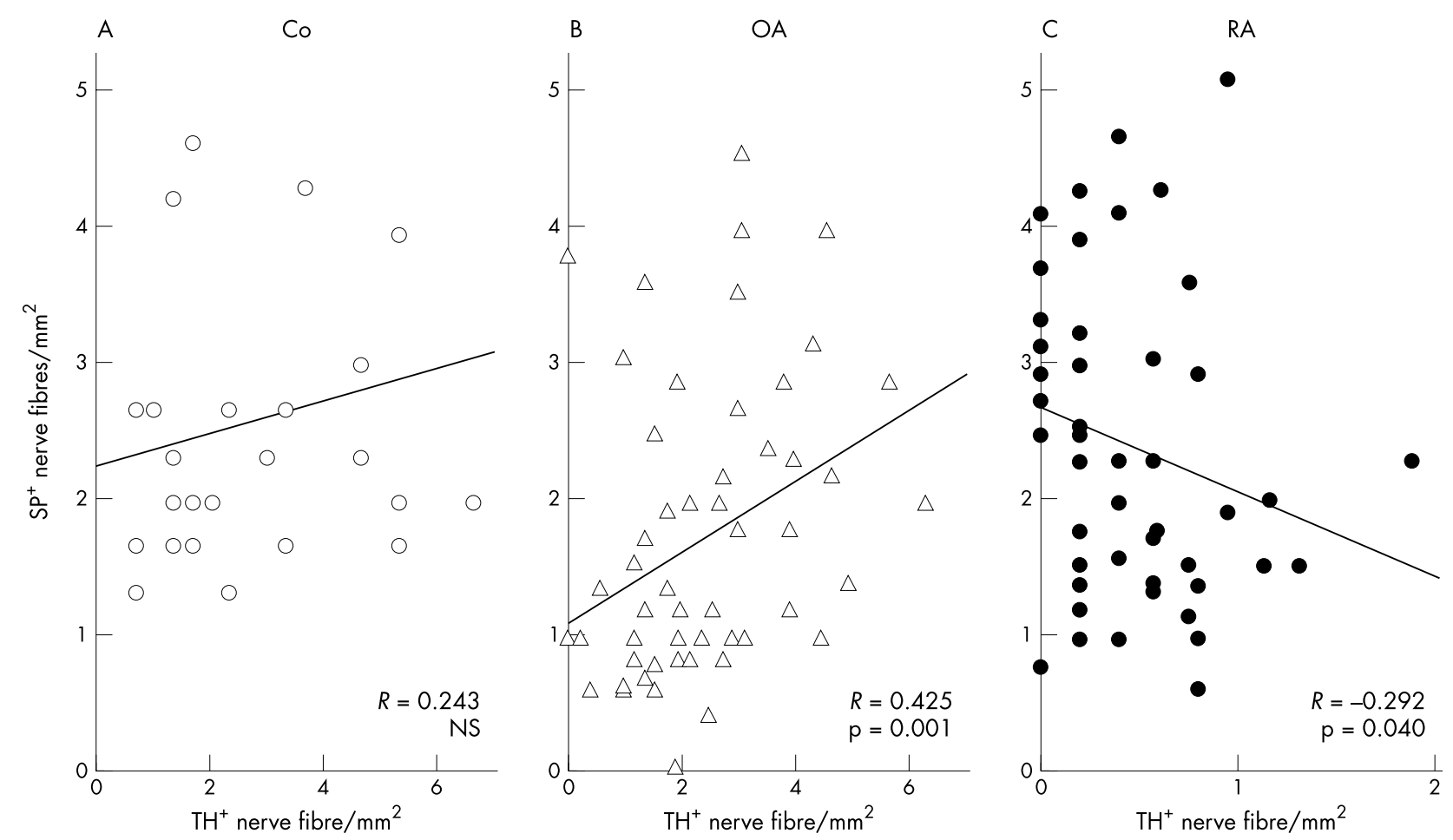

Figure 3 Interrelation between density of sympathetic $\mathrm{TH}^{+}$nerve fibres and density of $\mathrm{SP}^{+}$sensory nerve fibres in $(\mathrm{A})$ control subjects (Co); (B) patients with OA; and (C) patients with RA. The linear regression line and its Pearson correlation coefficient are given.

mounted onto gelatin coated microscope slides that were stored at $-80^{\circ} \mathrm{C}$ until required. In situ hybridisation histochemistry was carried out as described previously. ${ }^{30}$ Briefly, the sections were taken through a series of dehydrating alcohol washes, air dried, and a $\left[{ }^{35} \mathrm{~S}\right] \mathrm{dATP}$ $3^{\prime}$ end labelled oligonucleotide BDNF probe added in hybridisation buffer. The probe sequence was 5'-CCA-GTGCCT-CTT-GTC-TAT-GCC-CCT-GCA-GCC-CTC-CTT-TGT-GTACCC-CAT-3', representing nucleotides 746-795. ${ }^{31}$ The sections were incubated overnight at $37^{\circ} \mathrm{C}$ before washing to remove unbound and non-specifically bound probe. The sections were dried and exposed to autoradiography film. Further sections were dipped in photographic emulsion to visualise cellular distribution of the probe bound. Counter staining was carried out with haematoxylin and eosin.

\section{Presentation of data and statistical analysis}

Data are presented as mean (SEM). Groups were compared by the non-parametric Mann-Whitney test, correlations were calculated by Pearson's correlation analysis (SPSS/PC, version 11.5, SPSS Inc, Chicago, USA). Frequencies in two different groups were compared by $\chi^{2}$ test using Yates's continuity correction or Fisher's exact test if possible. $\mathrm{p}<0.05$ was the level of significance.

We used the ratio "density of sympathetic $\mathrm{TH}^{+}$nerve fibres/ density of $\mathrm{SP}^{+}$sensory nerve fibres" in order to demonstrate the relation between both types of nerve fibre (values are without units). ${ }^{15}$ To investigate the interrelation between the density of $\mathrm{BDNF}^{+}$cells and the density of sympathetic $\mathrm{TH}^{+}$ or $\mathrm{SP}^{+}$sensory nerve fibres, we used correlation analysis ( $\mathrm{x}$ value: density of $\mathrm{BDNF}^{+}$cells; y value: above mentioned nerve fibre ratio) and a ternary plot ( $x$ value: density of $\mathrm{BDNF}^{+}$cells; $\mathrm{y}$ value: density of sympathetic $\mathrm{TH}^{+}$nerve fibres; $\mathrm{Z}$ value: density of $\mathrm{SP}^{+}$sensory nerve fibres). A ternary plot is an analytical and plotting application that normalises and plots three values on a triangular diagram and three bivariate cross plots. In the plot, means and standard deviations are calculated in the normalised space (see http:/home.c2i. net/astandne/help_htm/english/terplotl.htm; accessed 27 September 2004). The ternary diagram was created using the standard ternary plot software of SigmaPlot 2002 (SPSS Inc, Chicago, USA).

\section{RESULTS}

\section{Sympathetic and $\mathrm{SP}^{+}$sensory innervation of synovial} tissue

Figure 1 shows representative immunohistochemical stainings of $\mathrm{SP}^{+}$sensory nerve fibres and sympathetic $\mathrm{TH}^{+}$nerve fibres. Note the typical pattern of $\mathrm{TH}^{+}$staining which follows larger arteries (fig 1). A significant reduction of $\mathrm{SP}^{+}$sensory nerve fibres was found in patients with OA compared with patients with RA or control subjects with non-inflammatory conditions (fig 2A). This indicates a reduction of $\mathrm{SP}^{+}$sensory innervation in patients with OA. For sympathetic synovial innervation, there was a clear reduction of sympathetic $\mathrm{TH}^{+}$ nerve fibres in patients with RA as compared with patients with $\mathrm{OA}$ and controls (fig 2B). No difference was seen between patients with $\mathrm{OA}$ and control subjects (fig 2B). The ratio of the density of sympathetic $\mathrm{TH}^{+}$nerve fibres/ $\mathrm{SP}^{+}$ sensory nerve fibres was markedly lower in patients with RA than in patients with OA and controls (fig 2C). Interestingly, patients with OA had a significantly higher ratio than controls (fig 2C), which indicates that patients with OA had the highest density of sympathetic in relation to $\mathrm{SP}^{+}$ sensory nerve fibres when compared with the other two groups.

Correlation analysis showed a trend for a positive interrelation between sympathetic $\mathrm{TH}^{+}$nerve fibres and $\mathrm{SP}^{+}$ sensory nerve fibres in control subjects (fig 3A) and in patients with OA (fig 3B). In patients with RA, this interrelation was negative, which indicates inverse coupling of sympathetic and $\mathrm{SP}^{+}$sensory nervous inputs to $\mathrm{RA}$ synovium (fig 3C). 
A
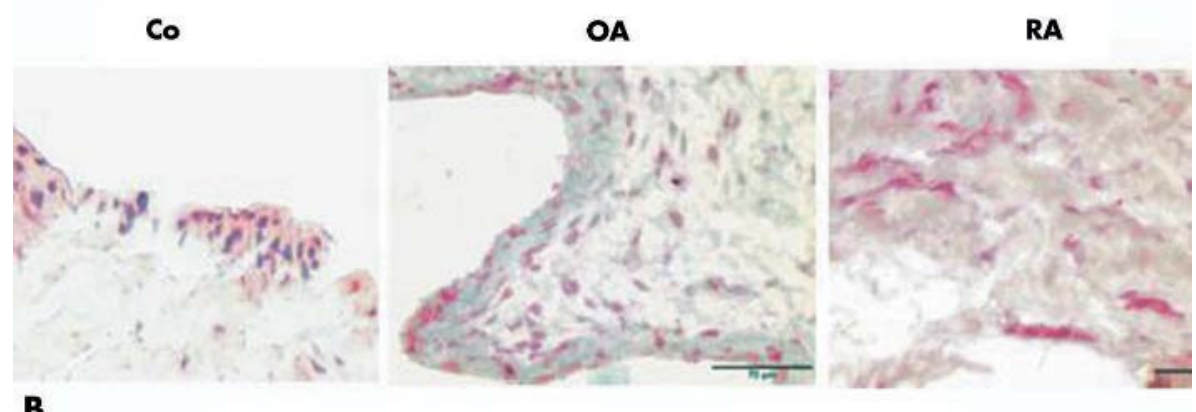

OA

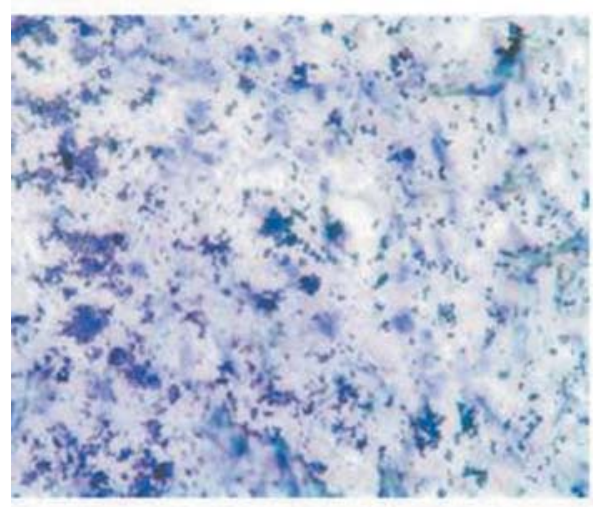

C

BDNF + / Fibroblasts

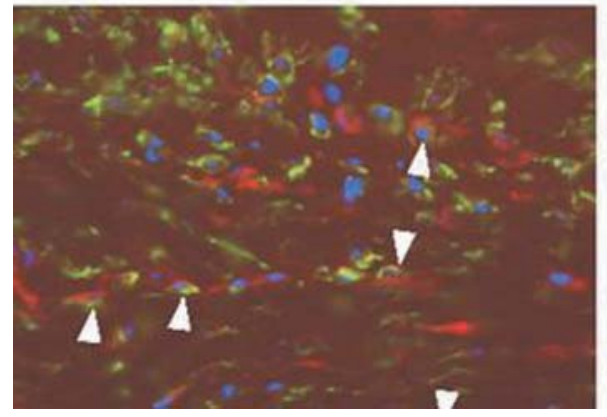

RA

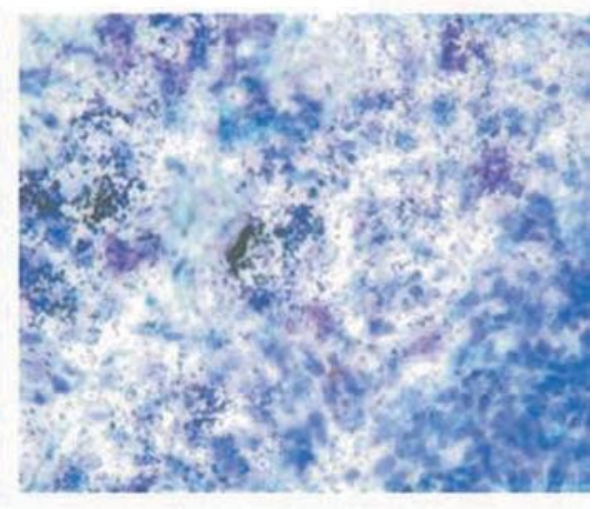

BDNF $^{+} /$Macrophages

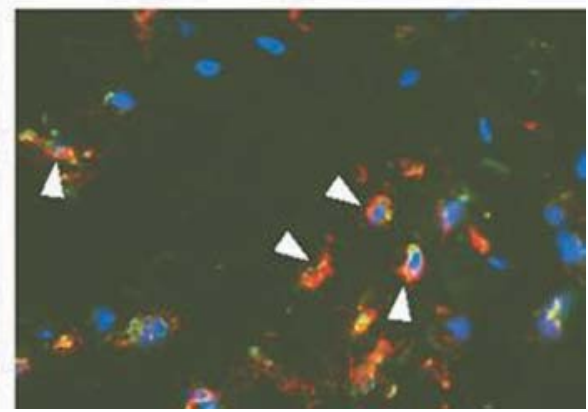

Figure 4 Immunohistochemistry of BDNF in synovial tissue. (A) Synovial tissue from a control subject without an inflammatory condition (Co), a patient with OA, and a patient with RA stains positive for BDNF. APAAP staining was used. (B) BDNF in situ hybridisation of synovial tissue from a patient with $\mathrm{OA}$ and RA. (C) Immunofluorescence double staining of $\mathrm{BDNF}^{+}$cells (green fluorescence) versus fibroblasts (left panel: red fluorescence, prolyl-4hydroxylase) or macrophages (right panel: red fluorescence, CD163). Nuclei were stained with DAPI. In all panels, respective control stainings were always negative. All micrographs were taken at $\times 400$ magnification.

In a receiver operator curve analysis including all investigated subjects, both the density of sympathetic nerve fibres and the ratio of the density of sympathetic nerve fibres divided by the density of $\mathrm{SP}^{+}$nerve fibres turned out to be excellent variables to separate patients with RA from either patients with OA or control subjects. In this analysis, it was found that a cut off value of 0.94 for the density of sympathetic nerve fibres yielded the highest sensitivity of $92.0 \%$, a specificity of $87.8 \%$, and an accuracy of $89.4 \%$. When the nerve fibre ratio was used as the variable, it was found that a cut off value of 0.50 yielded the highest sensitivity of $84.0 \%$, a specificity of $85.4 \%$, and an accuracy of $84.8 \%$.

Because the control patients were markedly different in age, we investigated whether an interrelation existed between age and nerve fibre density in the various patient subgroups: no such correlation was found for control subjects (age $v \mathrm{TH}^{+}: R=0.192, \mathrm{p}=0.348 ;$ age $v \mathrm{SP}^{+}: R=-0.056$, $\mathrm{p}=0.785$ ), patients with OA (age $v \mathrm{TH}^{+}: R=0.243, \mathrm{p}=0.069$; age $v \mathrm{SP}^{+}: R=0.127, \mathrm{p}=0.342$ ), and patients with RA (age $v$ $\mathrm{TH}^{+}: R=-0.090, \mathrm{p}=0.525 ;$ age $\left.v \mathrm{SP}^{+}: R=0.158, \mathrm{p}=0.273\right)$.

In another analysis we compared women and men in order to investigate a possible difference in nerve fibre density. We detected no difference for density of sympathetic $\mathrm{TH}^{+}$nerve fibres and $\mathrm{SP}^{+}$sensory nerve fibres between women and men in the different patient groups ( $p$ values at least $>0.20$, data not shown).

\section{$\mathrm{BDNF}^{+}$cells in synovial tissue}

Neurotrophic factors such as BDNF may potentially influence the growth of sympathetic and $\mathrm{SP}^{+}$sensory nerve fibres in a very differential way (supporting the growth of one, inhibiting the other). To link the expression of BDNF to 


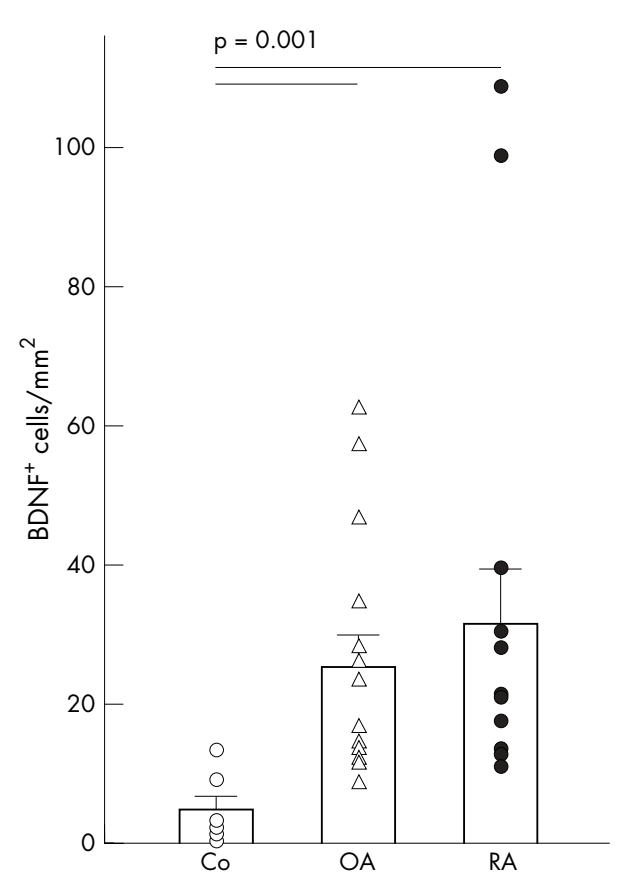

Figure 5 Density of $\mathrm{BDNF}^{+}$cells in control subjects $(\mathrm{Co})$, patients with $\mathrm{OA}$, and patients with RA. Values of $\mathrm{p}$ for comparison of group medians are given.

sympathetic and $\mathrm{SP}^{+}$sensory nerve fibres, BDNF was detected immunohistochemically: $\mathrm{BDNF}^{+}$cells were found in all three patient groups (fig 4A). In all three patient groups, BDNF cells were located in the lining area (fig 4A). However, only in patients with RA and OA were the cells in the synovial sublining area stained positive for BDNF (fig 4A). A representative in situ hybridisation of OA and RA synovial sublining tissue demonstrated marked expression of BDNF mRNA (fig 4B). Immunohistochemical double staining confirmed that $\mathrm{BDNF}^{+}$cells most often stained positive also for markers of fibroblasts (prolyl-4-hydroxylase) and macrophages (CD163), respectively (fig 4C). Furthermore, there was a highly significant increase in the density of $\mathrm{BDNF}^{+}$cells in patients with RA and OA in comparison with control subjects (fig 5). This indicates that BDNF is particularly expressed under more inflammatory conditions. In the different groups, age and sex were not related to the density of $\mathrm{BDNF}^{+}$cells (data not shown).

\section{Interrelation between $\mathrm{BDNF}^{+}$cells and sympathetic $\mathrm{TH}^{+}$or $\mathrm{SP}^{+}$sensory nerve fibres}

A correlation analysis for the density of $\mathrm{BDNF}^{+}$cells and the nerve fibre ratio demonstrated a positive interrelation in control subjects and patients with OA (figs 6A and B), but no such relationship existed in patients with RA (fig 6C). In controls and patients with OA this indicates that increased density of $\mathrm{BDNF}^{+}$cells is linked to a higher ratio of sympathetic nerve fibres to $\mathrm{SP}^{+}$sensory nerve fibres.

In the ternary plot, control subjects clearly differed from patients with RA and OA. This is demonstrated by the lower density of BDNF${ }^{+}$cells and higher density of sympathetic $\mathrm{TH}^{+}$ nerve fibres (fig 6D, open circles). Patients with RA and some patients with OA had a high density of $\mathrm{BDNF}^{+}$cells and very low density of sympathetic $\mathrm{TH}^{+}$nerve fibres (fig 6D, red circles and black triangles in lower left corner). A subgroup of patients with $\mathrm{OA}$ exists who had an intermediate pattern (fig 6D, black triangles, between lower left corner and control subjects).

\section{DISCUSSION}

This is the first study which has demonstrated similar synovial density of sympathetic nerve fibres in a control group without inflammation in comparison with patients with OA. This analysis was important in order to give an unbiased absolute measure of the density of sympathetic nerve fibres in non-inflamed synovial tissue. In addition, we confirmed the striking loss of sympathetic nerve fibres in patients with $\mathrm{RA}^{14}{ }^{15}$ as compared with patients with OA and control subjects.

In animal studies, reduction of nerve fibre density was dependent on the stage of the disease. ${ }^{32}$ However, we were unable to link reduction of sympathetic nerve fibres to markers of inflammation or disease duration. Our patients had long term disease, and it seems that in this stage of the disease sympathetic nerve fibres are almost absent. In control subjects and patients with OA, the densities of sympathetic and $\mathrm{SP}^{+}$sensory nerve fibres were positively correlated, whereas in patients with RA this correlation was negative.

Because high levels of sympathetic neurotransmitters inhibit many immunological functions, particularly, those of the innate immune system, ${ }^{1-11}$ a normal density of sympathetic nerve fibres of about 2.6 nerve fibres $/ \mathrm{mm}^{2}$ may be necessary for a balanced immune reaction ( = the value of the control subjects). This is particularly important because the density of proinflammatory $\mathrm{SP}^{+}$sensory nerve fibres remains unaltered. ${ }^{14}{ }^{15}$ It is important to mention that low concentrations of norepinephrine $\left(<10^{-7} \mathrm{~mol} / \mathrm{l}\right.$, via $\alpha$-adrenoceptors) and adenosine $\left(<10^{-7} \mathrm{~mol} / \mathrm{l}\right.$, via $\mathrm{Al}$ adenosine receptors) can exert a completely opposite, now proinflammatory influence on the immune system (summarised by Straub and Cutolo $^{12}$ ). The equilibrium, as estimated by the ratio of the density of sympathetic to the density of $\mathrm{SP}^{+}$sensory nerve fibres in control subjects and patients with OA, is typically above $0.50-1.00$. We may speculate that under normal conditions this equilibrium is maintained in order to establish a balanced tissue supply. This balance is largely shifted to proinflammatory $\mathrm{SP}^{+}$ sensory nerve fibres in patients with RA. At this point the question arises why, in this inflammatory process, the density of sympathetic nerve fibres decreases and the density of $\mathrm{SP}^{+}$sensory nerve fibres remains constant.

The presence of nerve fibres in peripheral tissue is controlled by nerve growth factors and nerve repellent factors. It has been repeatedly demonstrated that NGF is present in inflamed synovial tissue and fluid in $\mathrm{RA}^{23}$ in circulating blood, ${ }^{33}$ and in the synovial fluid of patients with spondyloarthropathies. ${ }^{34}$ NGF is produced by different leucocytes upon stimulation (see, for example, Pezzati et a ${ }^{35}$ and Morgan et $a l^{36}$ ), and was found to be an important stimulator of wound healing. ${ }^{37-39}$ In contrast with NGF, the presence of BDNF has never been described in synovial tissue in animals or men. BDNF is up regulated in rat dorsal root ganglia after acute peripheral inflammation. ${ }^{25}$ Activated cells of the immune system express BDNF, ${ }^{26}{ }^{27}$ and BDNF was found in inflammatory lesions. ${ }^{26}{ }^{28}$ Both BDNF and NGF are up regulated in inflammatory lesions. Our study demonstrated increased density of $\mathrm{BDNF}^{+}$cells in inflamed synovium of patients with RA and OA but not in control subjects. The difference was most pronounced in the sublining area, and both fibroblasts and macrophages stained positive for BDNF.

Moreover, we tried to link cellular expression of BDNF to the described dissociation of sympathetic versus $\mathrm{SP}^{+}$sensory nerve fibres. The analysis showed that the density of $\mathrm{BDNF}^{+}$ cells is positively related to the increased density of sympathetic in relation to $\mathrm{SP}^{+}$sensory nerve fibres in control subjects and patients with OA, but not in patients with RA. One may speculate that BDNF supports the growth of 

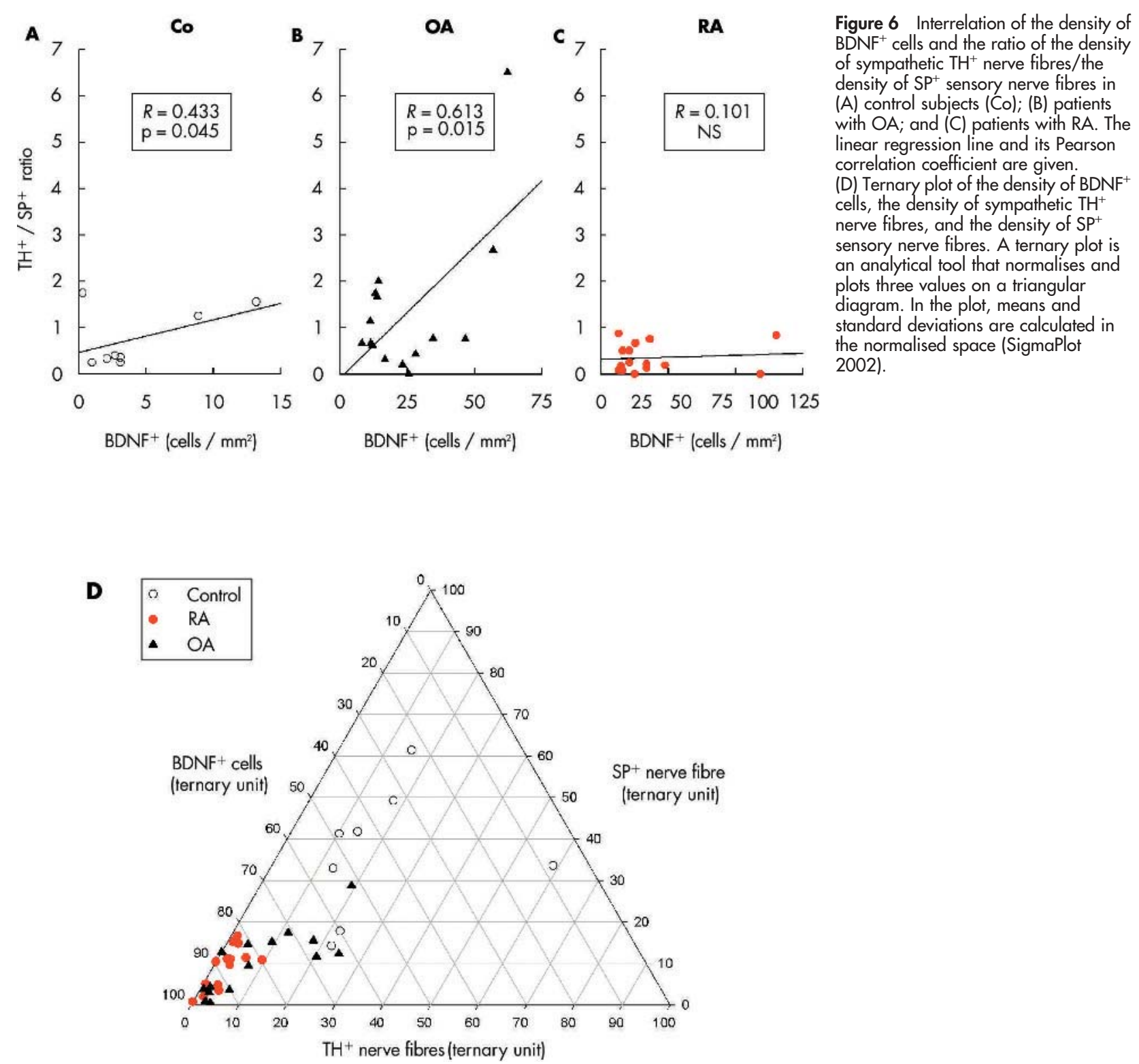

sympathetic nerve fibres more than the growth of $\mathrm{SP}^{+}$ sensory nerve fibres, which may be disrupted in patients with RA. As patients with RA in comparison with OA and controls demonstrate increased density of the sympathetic nerve repellent factor semaphorin $3 \mathrm{C}$ in synovial tissue, ${ }^{18}$ the presence of BDNF may not influence the growth of sympathetic nerve fibres in the same way as in controls and patients with OA.

Although the deductive nature of our approach does not allow us to find a causative relationship between BDNF and nerve fibre dissociation, it stimulates new ideas for following up this intriguing subject in experimental models of arthritis. In addition, the decrease of visible nerve fibres may also depend on exaggerated release of neuropeptides or alterations of expression of key enzymes such as TH during the inflammatory process. ${ }^{16}{ }^{17}$ Nevertheless, it seems obvious that the detected loss of visible nerve fibres is probably linked to functional alterations of these neuronal pathways.

A second interesting finding was the decreased density of $\mathrm{SP}^{+}$sensory nerve fibres in patients with $\mathrm{OA}$ as compared with control subjects and patients with RA. At present, we do not know how the loss of $\mathrm{SP}^{+}$sensory nerve fibres influences the osteoarthritic process but one may speculate that loss of joint sensation would lead to continuous mechanical microtraumas. ${ }^{40}{ }^{41}$ Furthermore, loss of SP may lead to a lack of growth promoting factors because SP can stimulate extracellular matrix production etc. ${ }^{42-44}$ Both conditions may lead to a loss of joint protection in patients with OA.

In conclusion, the interrelation of the density of $\mathrm{SP}^{+}$ sensory and sympathetic nerve fibres was positive in control subjects and OA but negative in RA, which demonstrates inverse coupling of these two nervous systems in RA synovium. BDNF, a neurotrophic factor, may have a stimulatory role on the growth of sympathetic in relation to $\mathrm{SP}^{+}$sensory nerve fibres in control subjects and $\mathrm{OA}$, which may not be the case in RA. Further studies will be needed to prove whether BDNF is a relevant cofactor for the observed dissociation of sympathetic versus $\mathrm{SP}^{+}$sensory nerve fibres in animal models of arthritis.

\section{ACKNOWLEDGEMENTS}

Part of this study were funded by the Deutsche Forschungsgemeinschaft (Str 511/10-1) and by the respective institutions. 


\section{Authors' affiliations}

C Weidler, C Holzer, J Schölmerich, R H Straub, Department of Internal Medicine I, University Hospital, 93042 Regensburg, Germany

M Harbuz, Department of Clinical Medicine, University of Bristol, Bristol, BS1 3NY, UK

R Hofbaver, Department of Orthopaedic Surgery, University of Regensburg, 93042 Regensburg, Germany

P Angele, Department of Trauma Surgery, University of Regensburg, 93042 Regensburg, Germany

\section{REFERENCES}

1 Renz H, Gong JH, Schmidt A, Nain M, Gemsa D. Release of tumor necrosis factor-alpha from macrophages. Enhancement and suppression are dosedependently regulated by prostaglandin E2 and cyclic nucleotides. J Immunol 1988;141:2388-93.

2 Le Moine O, Stordeur P, Schandene L, Marchant A, De Groote D, Goldman M, et al. Adenosine enhances IL-10 secretion by human monocytes. J Immunol 1996; 156:4408-14.

3 Guirao X, Kumar A, Katz J, Smith M, Lin E, Keogh C, et al. Catecholamines increase monocyte TNF receptors and inhibit TNF through beta 2adrenoreceptor activation. Am J Physiol 1997;273:E1 203-8.

4 Straub RH, Günzler C, Miller LE, Cutolo M, Schölmerich J, Schill S. Antiinflammatory cooperativity of corticosteroids and norepinephrine in rheumatoid arthritis synovial tissue in vivo and in vitro. FASEB $J$ 2002; 16:993-1000.

5 Weiss M, Schneider EM, Liebert S, Mettler S, Lemoine H. Vasoactive drugs inhibit oxygen radical production of neutrophils. Immunopharmacol Immunotoxicol 1997;19:239-63.

6 Kubersky SM, Hirschhorn R, Broekman MJ, Cronstein BN. Occupancy of adenosine receptors on human neutrophils inhibits respiratory burst stimulated by ingestion of complement-coated particles and occupancy of chemoattractant but not Fc receptors. Inflammation 1989;13:591-9.

7 Fredholm BB, Zhang Y, van der Ploeg I. Adenosine A2A receptors mediate the inhibitory effect of adenosine on formyl-Met-Leu-Phe-stimulated respiratory burst in neutrophil leucocytes. Naunyn Schmiedebergs Arch Pharmacol 1996;354:262-7

8 Whalen MM, Bankhurst $A D$. Effects of beta-adrenergic receptor activation, cholera toxin and forskolin on human natural killer cell function. Biochem $J$ 1990;272:327-31.

9 Schedlowski M, Falk A, Rohne A, Wagner TO, Jacobs R, Tewes U, et al. Catecholamines induce alterations of distribution and activity of human natural killer (NK) cells. J Clin Immunol 1993;13:344-51

10 Nair MP, Schwartz SA, Wu K, Kronfol Z. Effect of neuropeptide Y on natural killer activity of normal human lymphocytes. Brain Behav Immun 1993;7:70-8.

11 Priebe T, Kandil O, Nakic M, Pan BF, Nelson JA. Selective modulation of antibody response and natural killer cell activity by purine nucleoside analogues. Cancer Res 1988;48:4799-803.

12 Straub RH, Cutolo M. Involvement of the hypothalamic-pituitary-adrenal/ gonadal axis and the peripheral nervous system in rheumatoid arthritis: viewpoint based on a systemic pathogenetic role. Arthritis Rheum 2001;44:493-507.

13 Pereira da Silva JA, Carmo-Fonseca M. Peptide containing nerves in human synovium: immunohistochemical evidence for decreased innervation in rheumatoid arthritis. J Rheumatol 1990;17:1592-9.

14 Miller LE, Jüsten HP, Schölmerich J, Straub RH. The loss of sympathetic nerve fibers in the synovial tissue of patients with rheumatoid arthritis is accompanied by increased norepinephrine release from synovial macrophages. FASEB J 2000; 14:2097-107.

15 Miller LE, Grifka J, Schölmerich J, Straub RH. Norepinephrine from synovial tyrosine hydroxylase positive cells is a strong indicator of synovial inflammation in rheumatoid arthritis. J Rheumatol 2002;29:427-35.

16 Konttinen YT, Kemppinen P, Segerberg M, Hukkanen M, Rees R, Santavirta S, et al. Peripheral and spinal neural mechanisms in arthritis, with particular reference to treatment of inflammation and pain. Arthritis Rheum 1994:37:965-82.

17 Matucci-Cerinic M, Konttinen Y, Generini S, Cutolo M. Neuropeptides and steroid hormones in arthritis. Curr Opin Rheumatol 1998; 10:220-35.

18 Miller LE, Weidler C, Falk W, Angele P, Schaumburger J, Scholmerich J, et al. Increased prevalence of semaphorin 3C, a repellent of sympathetic nerve fibers, in the synovial tissue of patients with rheumatoid arthritis. Arthritis Rheum 2004;50:1156-63.
19 Kirstein M, Farinas I. Sensing life: regulation of sensory neuron survival by neurotrophins. Cell Mol Life Sci 2002;59:1787-802.

20 Barbacid M. The Trk family of neurotrophin receptors. J Neurobiol 1994;25:1386-403.

21 Chalazonitis A. Neurotrophin-3 as an essential signal for the developing nervous system. Mol Neurobiol 1996; 12:39-53.

22 Shu XQ, Mendell LM. Neurotrophins and hyperalgesia. Proc Natl Acad Sci USA 1999;96:7693-6.

23 Aloe L, Tuveri MA, Carcassi U, Levi-Montalcini R. Nerve growth factor in the synovial fluid of patients with chronic arthritis. Arthritis Rheum 1992;35:351-5.

24 Braun A, Lommatzsch M, Lewin GR, Virchow JC, Renz H. Neurotrophins: a link between airway inflammation and airway smooth muscle contractility in asthma? Int Arch Allergy Immunol 1999;118:163-5.

25 Cho HJ, Kim JK, Zhou XF, Rush RA. Increased brain-derived neurotrophic factor immunoreactivity in rat dorsal root ganglia and spinal cord following peripheral inflammation. Brain Res 1997;764:269-72.

26 Kerschensteiner M, Gallmeier E, Behrens L, Leal WV, Misgeld T, Klinkert WE et al. Activated human T cells, B cells, and monocytes produce brain-derived neurotrophic factor in vitro and in inflammatory brain lesions: a neuroprotective role of inflammation? J Exp Med 1999;189:865-70.

27 Barouch R, Appel E, Kazimirsky G, Braun A, Renz H, Brodie C. Differential regulation of neurotrophin expression by mitogens and neurotransmitters in mouse lymphocytes. J Neuroimmunol 2000;103:112-21.

28 Toma H, Winston JH, Micci MA, Li H, Hellmich HL, Pasricha PJ. Characterization of the neurotrophic response to acute pancreatitis. Pancreas 2002;25:31-8.

29 Arnett FC, Edworthy SM, Bloch DA, McShane DJ, Fries JF, Cooper NS, et al. The American Rheumatism Association 1987 revised criteria for the classification of rheumatoid arthritis. Arthritis Rheum 1988;31:315-24

30 Harbuz MS, Lightman SL. Responses of hypothalamic and pituitary mRNA to physical and psychological stress in the rat. J Endocrinol 1989;122:705-11.

31 Leibrock J, Lottspeich F, Hohn A, Hofer M, Hengerer B, Masiakowski P, et al. Molecular cloning and expression of brain-derived neurotrophic factor. Nature 1989;341:149-52.

32 Imai S, Tokunaga Y, Konttinen YT, Maeda T, Hukuda S, Santavirta S. Ultrastructure of the synovial sensory peptidergic fibers is distinctively altered in different phases of adjuvant induced arthritis in rats: ultramorphological characterization combined with morphometric and immunohistochemical study for substance $P$, calcitonin gene related peptide, and protein gene product 9.5. J Rheumatol 1997:24:2177-87.

33 Matucci-Cerinic M, Giacomelli R, Pignone A, Cagnoni ML, Generini S, Casale $R$, et al. Nerve growth factor and neuropeptides circulating levels in systemic sclerosis (scleroderma). Ann Rheum Dis 2001;60:487-94

34 Dicou E, Perrot S, Menkes CJ, Masson C, Nerriere V. Nerve growth factor (NGF) autoantibodies and NGF in the synovial fluid: implications in spondylarthropathies. Autoimmunity 1996;24:1-9.

35 Pezzati P, Stanisz AM, Marshall JS, Bienenstock J, Stead RH. Expression of nerve growth factor receptor immunoreactivity on follicular dendritic cells from human mucosa associated lymphoid tissues. Immunology 1992;76:485-90.

36 Morgan B, Thorpe LW, Marchetti D, Perez-Polo JR. Expression of nerve growth factor receptors by human peripheral blood mononuclear cells. J Neurosci Res 1989;23:41-5.

37 Li AK, Koroly MJ, Schattenkerk ME, Malt RA, Young M. Nerve growth factor: acceleration of the rate of wound healing in mice. Proc Natl Acad Sci USA 1980;77:4379-81.

38 Lawman MJ, Boyle MD, Gee AP, Young M. Nerve growth factor accelerates the early cellular events associated with wound healing. Exp Mol Pathol 1985;43:274-81

39 Tuveri M, Generini S, Matucci-Cerinic M, Aloe L. NGF, a useful tool in the treatment of chronic vasculitic ulcers in rheumatoid arthritis. Lancet 2000;356:1739-40

40 O'Connor BL, Brandt KD. Neurogenic factors in the etiopathogenesis of osteoarthritis. Rheum Dis Clin North Am 1993;19:581-605.

41 O'Connor BL, Visco DM, Brandt KD, Myers SL, Kalasinski LA. Neurogenic acceleration of osteoarthrosis. The effects of previous neurectomy of the articular nerves on the development of osteoarthrosis after transection of the anterior cruciate ligament in dogs. J Bone Joint Surg Am 1992;74:367-76.

42 Nilsson J, von Euler AM, Dalsgaard CJ. Stimulation of connective tissue cell growth by substance $P$ and substance K. Nature 1985;315:61-3.

43 Ziche M, Morbidelli L, Pacini M, Dolara P, Maggi CA. NK1-receptors mediate the proliferative response of human fibroblasts to tachykinins. BrJ Pharmacol 1990;100:11-4.

44 Katayama I, Nishioka K. Substance P augments fibrogenic cytokine-induced fibroblast proliferation: possible involvement of neuropeptide in tissue fibrosis. J Dermatol Sci 1997;15:201-6. 